\title{
NILAI-NILAI PENDIDIKAN TAUHID IMAM AHMAD BIN HAMBAL
}

\author{
Ali Imron \\ Universitas Wahid Hasyim Semarang \\ aliimron.aya@gmail.com
}

\begin{abstract}
This paper aims to describe the values of tauhid education from the perspective of Imam Ahmad bin Hanbal. This is done because during this time Imam Ahmad bin Hambal is more popular as a scholar of Hadith and / or scholar of figh. On the other hand, the educational process experienced and received by Imam Ahmad bin Hanbal is rarely revealed in specific studies including studies on the values of his tawhid education. The researcher conducted a qualitative literature review of various literatures related to the values of Tawheed Education and associated with Imam Ahmad bin Hambal. Based on the descriptive analysis carried out, it was found that tauhid education is a process of cultivating monotheism on the oneness of Allah SWT. This is important to instill in humans, especially Muslims from an early age. Imam Ahmad bin Hanbal as one of the scholars of fiqh has an opinion that is not much different from other fiqh scholars about tawhid and the values of tawhid education. This is emphasized in his statement, namely believing only in Allah SWT, believing in the oneness of Allah and Allah who is the creator of the universe, and believing in the names and attributes of Allah SWT that are in the Al-Quran. The values of Imam Ahmad bin Hanbal's monotheistic education can be grouped into three main values, namely: the values of the behavior of a Muslim in relation to Allah SWT, himself and to fellow humans.
\end{abstract} Keywords: Educational Values, Tawheed, Imam Ahmad bin Hambal.

\begin{abstract}
Abstrak
Tulisan ini bertujuan untuk menguraikan nilai-nilai pendidikan tauhid Imam Ahmad bin Hanbal. Hal ini dilakukan karena selama ini Imam Ahmad bin Hambal lebih popular sebagai ulama Hadits dan atau ulama fiqih. Di sisi lain proses pendidikan yang dialami dan terima oleh Imam ahmad bin Hanbal jarang terungkap dalam kajian secara khusus termasuk kajian tentang nilainilai pendidikan tauhidnya. Peneliti melakukan kajian kualitatif pustaka terhadap berbagai literatur yang berkaitan dengan nilai-nilai Pendidikan Tauhid dan dihubungkan dengan Imam Ahmad bin Hambal. Berdasarkan analisis deskriptif yang dilakukan ditemukan hasil bahwa bahwasannya pendidikan tauhid merupakan proses penanaman ketauhidan atas keesaan Allah SWT. Ini penting untuk ditanamkan kepada manusia khususnya umat
\end{abstract}


Islam dari sejak dini sekalipun. Imam Ahmad bin Hanbal sebagai salah satu ulama fiqh memiliki pendapat yang tidak jauh berbeda dengan ulama fiqih lainnya tentang tauhid dan nilai-nilai pendidikan tauhid. Hal ini dipertegas dalam peryataannya yaitu beriman hanya kepada Allah SWT, yakin atas keesaan Allah dan Allah pencipta alam semesta, serta percaya akan namanama dan sifat-sifat Allah SWT yang ada di dalam Al-Qur'an. Nilai-nilai pendidikan tauhid Imam Ahmad bin Hanbal dapat dikelommpokkan menjadi tiga nilai utama yaitu: nilai-nilai perilaku seorang muslim dalam hubungannnya kepada Allah SWT, diri sendiri dan kepada sesama manusia. Kata Kunci: Nilai-Nilai Pendidikan, Tauhid, Imam Ahmad bin Hambal.

\section{A. Pendahuluan}

Manusia adalah mahluk Allah yang diciptakan secara sempurna (QS At-Tin: 4), dengan tujuan penciptaan sebagai hamba Allah (abdullah) (QS Adz Dzaariyaat : 56) sekaligus sebagai pemimpin bumi (khalifatullah fi al ard) (QS, Al-Baqarah : 30). Sebagai sarana menjalani dua misi penciptaan manusia tersebut pendidikan menjadi modal utamanya. Pendidikan sebagai proses pendewasaan manusia (peserta didik) yang meliputi aspek spiritual, intelektual dan emosional yang akan berdampak pada masa depannya, agama bahkan negaranya. Pendidikan tersebut dilaksanakan secara sistematis, terprogram, integral dan terpadu. ${ }^{1}$ Abu Ahmadi dan Nur Uhbiyati berpendapat bahwasannya pendidikan adalah suatu proses pembentukan kecakapan fundamental secara intelektual dan emosional manusia. ${ }^{2}$ Sedangkan menurut Choirul Anwar, pendidikan adalah proses pengubahan sikap dan tingkah laku seseorang atau kelompok dalam usaha mendewasakan manusia dengan cara pengajaran dan pelatihan. ${ }^{3}$

${ }^{1}$ Qiqi Yuliati Zakiyah dan A Rusdina, Pendidikan Nilai Kajian Teori dan Praktik di Sekolah, (Bandung: Pustaka Setia, 2014), hlm. 146.

${ }^{2}$ Abu Ahmadi, Nur Uhbiyati, Ilmu Pendidikan, (Jakarta: Rineka Cipta, 2015), hlm. 69.

${ }^{3}$ Choirul Anwar, Hakikat Manusia dalam Pendidikan Sebuah Tinjuan Filosofis, (Yogyakarta: Pustaka Setia, 2014), hlm. 68. 
Adapun tujuan pendidikan adalah pembentukan kepribadian, karakter, kemadirian dan keterampilan sosial. $^{4}$ Tujuan karakter dalam tujuan pendidikan merupakan bagian integral dari orientasi pendidikan Islam yaitu untuk membentuk yang berperilaku jujur, baik dan tanggungjawab, menghormati dan menghargai orang lain, adil, egaliter, pekerja keras, tidak diskriminatif dan karakter unggul lainnya. ${ }^{5}$

Nilai merupakan carapandang terhadap tindakan yang dilakukan seseorang sehingga dapat dijadikan pembeda sebagai sebuah pemikiran, perilaku, ide dan tindakan yang memiliki makna atau tidak. Nilai biasanya sesuatu yang berkaitan dengan karakter, akhlak dan moral. ${ }^{6}$

Berdasar pengertian di atas tentang pendidikan dan nilai diketahui bahwasannya pendidikan adalah proses penanaman atau internalisasi nilai-nilai spiritual, intelektual dan emosional kepada peserta didik yang disesuaikan dengan pandangan, norma, moral serta hal-hal yang dianggap baik oleh masyarakat.

Sedangkan nilai-nilai tauhid merupakan nilai dasar dan fundamental yang harus dimiliki manusia dalam menjalani kehidupan dan perkembangan serta perubahan social yang cepat sebagaimana saat ini. Tauhid adalah meyakini keesaan Allah dalam beribadah kepada-Nya. ${ }^{7}$ Tauhid merupakan ajaran pengakuan terhadap keesaan Allah secara konsekuensi dan murni. ${ }^{8}$

Adapun pendidikan tauhid menjadi upaya pengebangan fitrah manusia agar beriman dan mengesakan Allah, pendidikan tauhid

\footnotetext{
${ }^{4}$ M. Mahbudi, Pendidikan Karakter: Implementasi Aswaja sebagai Nilai Pendidikan Karakter, (Yogyakarta: Pustaka Ilmu, 2012), hlm. 37-38.

${ }^{5}$ Imam Syafe'i, Pondok Pesantren: Lembaga Pendidikan Pembentukan Karakter, Tadzkiyyah Jurnal Pendidikan Islam, Volume 8 No 1, November 2017, hlm. 63.

${ }^{6}$ Achmad Sanusi, Sistem Nilai Alternatif Wajah-wajah Pendidikan, (Bandung: Nuansa Cendikia, 2017), hlm. 145.

${ }^{7}$ Shalih, Kitab tauhid I, (Yogyakarta: Universitas Islam Indonesia, 2001), hlm. 19.

${ }^{8}$ Harun Nasution, Akal dan Wahyu dalam Islam, (Jakarta UI Press, 2011), hlm. 26.
} 
dilakukan dalam rangka menghilangkan segala hal yang negative, menumbuhkan hal-hal positif yang menjadikannya kekal dalam segala kondisi dan ruang. ${ }^{9}$

Shalih berpendapat bahwasannya tauhid adalah meyakini keesaan Allah dalam rububiyyah, ikhlas dalam beribadah kepada Allah dan menetapkan nama-nama dan sifat-sifat bagi Allah. ${ }^{10}$ Sedangkan Asy Syaikh Muhammad memiliki pandangan bahwa tauhid adalah mengesakan Allah dalam rububiyyah, uluhiyyah, nama dan sifat serta hukum Allah. ${ }^{11}$

Abu A'la al Maududi menjelaskan bahwasannya tauhid adalah deklarasi seorang Muslim, kalimat pembeda Muslim dengan kafir, ateis dengan musyrik. Sebuah perbedaan yang terletak pada peresapan makna dan meyakininya dengan sungguh-sungguh kebenarannya dan mewujdkannya ekdalam bentuk perbuatan sehingga tidak menyimpak dari ketetapan Ilahi. ${ }^{12}$ Sedangkan Muhammad Taqi MZ berpendapat bahwasannya pada intinya tauhid menghendaki agar seorang muslim menyerahkan segala urusan dan hatinya hanya kepada Allah SWT. ${ }^{13}$

Tauhid sebagai pilar penopang tindakan manusia, menjadi dasar semua pandangan tentang kebaikan, keteraturan, keterbukaan dan kepasrahan manusia kepada Allah dengan mematuhi sunatullah. ${ }^{14}$ Menurut empat mazhab fiqh yaitu bersaksi bahwa tiada Tuhan yang 10 .

${ }^{9}$ M Hamdani, Pendidikan Ketuhanan dalam Islam, (Surakarta: UMS Press, 2013), hlm.

${ }^{10}$ Shalih bin Fauzan, Kitab Tauhid Juz I, (Jakarta: Darul Haq, 2009), hlm. 19.

${ }^{11}$ Asy Syaikh Fauzan, al-Qoulul Mufid Penjelasan tentang Tauhid, (Bandung: Darul Ilmi, 2006), hlm. 136.

${ }^{12}$ Abu A'la al Maududi, Prinsip-prinsip Islam, Terj, Abdullah Suhaili, (Bandung: al Ma'arif, 1975), hlm. 68.

${ }^{13}$ Muhammad Taqi Misbah Yazid, Filsafat Tauhid, Terj., M. Ha bin Wicaksana, (Bandung: Mizan 2003), hlm. 61-63.

${ }^{14}$ Harun Nasution, Islam Rasional: Gagasan dan Pemikiran, (Jakarta: Mizan, 1996), hlm. 111. 
berhak diibadahi kecuali Allah, tiada sekutu bagi-Nya dan Muhammad adalah hamba dan utusan-Nya serta mengakui semua yang disampaikan para Nabi dan Rasul. ${ }^{15}$

Ilmu tauhid merupakan ilmu yang membahas ajaran dari suatu agama, ilmu ini akan menghantarkan seseorang yang ingin mengetahui dan menyelami seluk-beluk secara mendalam ketauhidan seseorang pada agama yang dianut. ${ }^{16}$

Dari penjelasan tauhid di atas, Nampak jelas bahwasannya tauhid lebih diartikan dengan teoantroposentris, pembahasannya berkutat pada pemusatan kepada Allah SWT dan manusia harus mengabdikan diri sepenuhnya kepada-Nya. Belum ada pembehasan yang menjadikan tauhid sebagai prinsip atas aspek kehidupan, aspek keluarga, Negara, ekonomi, social, politik dan sebagainya sebagai mana dilakukan oleh Ismail Raji alfaruqi. ${ }^{17}$

Perspektif empat mazhab fiqh, tauhid tidak memiliki perbedaan diantaranya, mereka sama-sama mengikuti al Qur'an dan as Sunah dan sesuai dengan pegangan sahabat serta tabi'in. Para imam mazhab mengelompokkan nilai-nilai pendidikan tauhid menjadi 3 yaitu nilai perilaku muslim kepada Allah, diri sendiri dan sesama.

Salah satu dari empat mazhab fiqh besar yang masih bertahan dan berkembang adalah Imam Ahmad bin Hambal, ia dikenal sebagai tokoh hadits $^{18}$ dan mujtahid besar dan ahl fiqh. ${ }^{19}$ Ahmad bin hambal

${ }^{15}$ Abdul Aziz Asy-Syinawi, Biografi Empat Imam Mazhab, (Jakarta: Ummul Qura, Cet. 1, 2017), hlm. 747.

${ }^{16}$ Mulyono dan bashori, Studi Ilmu Tauhid / Kalam, (Malang: UIN Maliki Press, 2010), hlm. 35 .

${ }^{17}$ Ismail Raji al-Faruqi, Tauhid, Terj. Rahmani Astuti, Bandung: Pustaka, Cet. 1, 1988.

${ }^{18}$ Abdul Karim, Manhaj Imam Ahmad ibn Hanbal dalam Kitab Musnad, RIWAYAH, $\begin{array}{lllll}\text { Vol. } & 1, & \text { No.2, } & \text { September } & 2015,\end{array}$ https://journal.iainkudus.ac.id/index.php/riwayah/is sue/view/170.

${ }^{19}$ Marzuki, Ahmad bin Hanbal (Pemikiran Fikih dan Ushul Fikihnya), Jurnal Hunafa, Vol. 2, No. Agustus 2005, 107-118. https://www.jurnalhunafa.org/index.php/hunafa. 
mendapatkan banyak pujian dari ulama, diantaranya dari Imam Syafi' I yaitu: "Ahmad bin hambal adalah imam dalam delapan hal: Imam dalam bidang hadits, fiqh, bahasa arab, al Qur'an, kefakiran, zuhud, wara' dan dalam berpegang teguh dengan sunnah Nabi”. ${ }^{20}$ Imam Ahmad ibn Hanbal memiliki sifat-sifat yang luhur dan tinggi, imam umat Islam, imam Darussalam, Mufti di Irak, Zahid dan saleh, sabar menghadapi cobaan, seorang ahli hadits dan contoh teladan bagi orang-orang yang ahli hadits. Sayyid Rasyid Ridho berpendapat bahwa Ahmad ibn Hanbal adalah seorang mujaddid (pembaharu) abad ketiga.Bahkan dalam pandangan peneliti lainnya berpendapat bahwa Imam Ahmad ibn Hanbal lebih utama, dengan gelar tersebut, dari pada Ibnu Suraij, Syafi'i, Thahawy, alKhilal dan an-Nasa'I. ${ }^{21}$

Berdasar latar belakang di atas, penulis tertarik untuk melakukan kajian secara literature tentang "Nilai-nilai Pendidikan Tauhid Perspektif Imam Ahmad bin Hambal".

\section{B. Pembahasan}

\section{Pendidikan Tauhid}

a. Pengertian Pendidikan Tauhid

Secara etimologi, pendidikan berasal bahasa Yunani yaitu pedagogie terdiri dari pais berarti anak dan again berarti membimbing. ${ }^{22}$ Dengan demikian pendidikan dapat diartikan sebagai suatu bimbingan yang diberikan kepada anak atau peserta didik sebagai proses / bimbingan untuk mengembangankan

${ }^{20}$ Abu Razin dan Nur Fajri Ramadhan, Pokok Akidah Ahlussunah - Imam Ahmad bin Hanbal (dengan Pendekatan Nahwu dan Sharaf), (Depok: BISA, Peserta Cet. 1, 2016), hlm. 7.

${ }^{21}$ Imam Munawwir, Mengenal Pribadi 30 Pendekar dan Pemikir Islam dari Masa ke Masa, (Surabaya: PT. Bina Ilmu, Cet. 1, 1985), hlm. 291. hlm. 23 .

${ }^{22}$ Abu Ahmadi dan Nur Uhbiyati, Ilmu Pendidikan Islam, (Jakarta: Rineka Cipta, 2013), 
potensi yang dimiliki. ${ }^{23}$ Ahmad tafsir memberikan pengertian pendidikan sebagai usaha membantu manusia menjadi manusia. ${ }^{24}$

Pendidikan adalah suatu aktifitas dalam mengembangakan aspek kepribadian manusia dan tidak berlangsung di kelas namun juga di luar kelas dikarenakan pelaksanaan pendidikan dapat diselenggarakan secara formal, informal dan non formal. ${ }^{25}$

Sedangkan tauhid atau ilmu tauhid terkadang disebut juga dengan ilmu kalam, yaitu ilmu yang membahas keesaan Allah SWT, di dalamnya dikaji tentang asma' Allah dan af'al Allah baik wajib, mustahil dan jaiz. Dibahsa juga sifat wajib, mustahil dan ja'iz bagi Rasullullah SAW. ${ }^{26}$ Secara bahasa, tauhid diartkan sebagai menjadikan sesuatu menjadi sesuatu. Dalam kamus Besar Bahasa Indonesia, tauhid merupakan kata benda yang berarti keesaan Allah; kuat kepercayaan bahwa Allah hanya satu. ${ }^{27}$ Secara istilah adalah mengesakan Allah di dalam rububiyyah, uluhiyyah, nama dan sifat serta hukum-Nya. ${ }^{28}$

Beberapa ahli mendefinisikan tauhid relative sama dengan pengertian di atas. Sebagaimana menurut Syaikh Muhammad Abduh dalam Sahilun Nasir 2010: 1, Abdul Azizi 2008: 31, Ibnu Khaldun 1986: 585 dan Shalih bin Fauzan 2009: 19 sama

${ }^{23}$ Hery Noer, Ilmu Pendidikan Islam, (Jakarta: Bumi Aksara, 2015), hlm. 6.

${ }^{24}$ Ahmad Tafsir, Filsafat Pendidikan Islam: Integrasi jasmani, Rohani dan Kalbu, (Bandung: Remaja Rosdakarya, 2010), hlm. 33.

${ }^{25}$ Zuhairini, Filsafat Pendidikan Islam, (Jakarta: Bumi Aksara, 2012), hlm. 149.

${ }^{26}$ Abdul Rozak dan Rosihan Anwar, Ilmu Kalam, (Bandung: Pustaka Setia, 2012), hlm. 26.

${ }^{27}$ M Yusran Asmunidari Tim Penyusun Kamus, kamus Besar Bahasa Indonesia, Jakarta: Departemen P\&K 1989, dalam Ilmu Tauhid, (Jakarta: Raja Grafindo Persada, 1993), hlm. 1.

${ }^{28}$ Asy Syaikh Muhammad, Al Qoulul Mufid Penjelasan tetang Tauhid, (Bandung: Darul Ilmi, 2006), hlm. 136. 
memberikan pengertian jika tauhid adalah ilmu yang membahas keesaan Allah SWT.

Dengan demikian pendidikan tauhid dapat difahami sebagai pengembangan fitrah manusia agar beriman dan mengesakan Allah SWT., sebagai upaya melenyapkan segala hal negative dengan hal positif untuk mengembangkan dan membimbing akal pikiran mengarah hanya kepada Allah dan mengekalkannya dalam segala kondisi dan ruang. ${ }^{29}$

Tauhid menjadi ajaran penting karena membahas tentang pengakuan terhadap keesaan Allah SWT secara murni. ${ }^{30}$ Tauhid menjadi basis utama seorang muslim, sebagaimana firman Allah SWT dalam QS al Ikhlas ayat 1-4 yang artinya:

"Katakanlah: "Dia-lah Allah, yang Maha Esa. Allah adalah Tuhan yang bergantung kepada-Nya segala sesuatu. Dia tiada beranak dan tidak pula diperanakkan, Dan tidak ada seorangpun yang setara dengan Dia”. Q.S.

Al-Ikhlas : $1-4 .{ }^{31}$

Dari ayat di atas, jelaslah jika tauhid merupakan ajaran penting yang memuat bahwasannya tidak ada Tuhan selain Allah dan kepada-Nya segala sesuatu bergantung.

b. Dasar dan Tujuan Pendidikan Tauhid

Dasar pendidikan tauhid sama dengan pendidikan Islam, sebab sumber utamanya sebagai dasar sama yaitu al Qur'an dan al Hadits. Dalam al Qur'an disebutkan salah satunya pada QS Luqman ayat 13 mengisahkan luqman yang mengajari anaknya tentang tauhid. Sebagaimana berikut: 10.

${ }^{29}$ M Hamdani, Pendidikan Ketuhanandalam Islam, (Surakarta: UMS Press, 2013), hlm.

${ }^{30}$ Harun Nasution, Akal dan Wahyu dalam Islam, (Jakarta UI Press, 2011), hlm. 16.

${ }^{31}$ Departemen Agama RI, Mushaf AL-Qur'an Terjemah, (Banadung: Diponegoro, 2014), hlm. 604. 
"dan (ingatlah) ketika Luqman berkata kepada anaknya, pada waktu ia memberikan pelajaran kepadanya: Hai anakku, janganlah kamu mempersekutukan Allah, sesungguhnya mempersekutukan Allah adalah benarbenar kezaliman yang besar". QS Luqman: $13 .^{32}$

Ayat di atas menejelaskan bagimana proses pendidikan tauhid yang dilaksanakan oleh Luqman selaku orang tua kepada anaknya tentang tauhid (pengesaan Tuhan), yaitu melarang anaknya berbuat syirik (memepersekutukan Allah) sebab perbuatan tersebut merupakan dosa besar. Untuk itu, memberikan pendidikan tauhid menjadi sangat penting baik dalam keluarga ataupun pada lingkungan pendidikan lain.

Pada ayat lain, tauhid diwujudkan dalam bentuk beribadah dengan menyembah dan minta pertolongan hanya kepada Allah sebagaimana disebutkan pada QS al Fatihah ayat 5:

"Hanya kepada Engkaulah kami menyembah dan hanya kepada Engkaulah kami memohon pertolongan". QS al Fatihah: $5 .{ }^{33}$

Ayat di atas secara tegas arti tauhid sebagai ibadah atau tauhid ilahiyyah, yaitu menjadikan Allah SWT sebagai Tuhan yang harus disembah dan mintai pertolongan. Tidak ada yang berhak disembah dan dimintai pertolongan selain Allah SWT. ${ }^{34}$

Dasar pendidikan tauhid selanjutnya adalah al hadits, yaitu hadits-hadits yang berisikan petunjuk untuk membina umat manusia agar menjadi manusia yang bertaqwa. Di antara hadits tersebut adalah hadits Jibril, hadits yang diriwayatkan oleh

\footnotetext{
${ }^{32}$ Departemen Agama RI, MushafAL-Qur'an Terjemah, (Bandung: Diponegoro, 2014), hlm. 412.

${ }^{33}$ Departemen Agama RI, MushafAL-Qur'an Terjemah, (Bandung: Diponegoro, 2014), hlm. 1.

${ }^{34}$ Yusuf al-Qaradhawi, Akidah Salaf dan Kholaf, (Jakarta: Pustaka al Kausar, 2006), hlm. 13.
} 
Muslim No 8 dan juga hadits yang diriwayatkan oleh Abu Hurairah dan dikeluarkan oleh Bukhari No. 50. ${ }^{35}$

Tujuan dalam pelaksanaan pendidikan adalah hal yang ingin dicapai dan wujudkan pada diri peserta didik setelah mengikuti pendidikan, rumusan tujuan pendidikn bersifat komprehensif, mencakup aspek yang terintegrasi dalam pola kepribadian yang ideal. Adapun tujuan pendidikan tauhid, menurut Zainuddin dalam bukuinya berjudul Ilmu Tauhid Lengkap adalah:

1) Tauhid yang tertanam pada jiwa seseorang akan mampu mengikuti petunjuk Allah SWT, memperoleh kepuasan batin, keselamatan di dunia serta akhirat.

2) Manusia terhindar dari pengaruh ajaran atau aqisah yang sesat

3) Manusia akan terhindar dari faham yang hanya sebatas kebendaan saja, seperti materialism, kapitalisme dan lainnya. ${ }^{36}$

Tujuan pendidikan tauhid perlu diperkenalkan kepada anak sejak dini (hadits perintah shalat), dengan begitu penanaman aqidah sejak dini ini akan menjadi kunci utama muslim menjalani kehidupan. Sebab tujuan pendidikan tauhid lainnya adalah suasana ideal yang akan ditampakkan dalam keyakinannya akan keesaan Allah SWT. ${ }^{37}$

c. Ruang Lingkup Pendidikan Tauhid

Objek pendidikan tauhid sebagai ruang lingkup kajiannya dibagi menjadi tiga bagian, yaitu: Tauhid Ilahiyah (Ketuhanan),

${ }^{35}$ Syahrizal Afandi, Kajian Hadits Jibril dalam Persepektif Pendidikan (Kajian Materi Pembelajaran dan Metode Pembelajaran), Jurnal Penelitian KeIslaman, Vol. 15, No.1, 2019, 30-31. https://journal.uinmataram.ac.id/index.php/jpk/article/view/525

${ }^{36}$ Zainuddin, Ilmu tauhid Lengkap, (Jakarta: Rineka Cipta, 2015), hlm. 8-9.

${ }^{37}$ Abdurrahman at-Tamimi, al-Mathlub al-Hamid fi Bayani Maqasid at-Tauhid, (Yogyakarta: Darul Hidayah, 1991), hlm. 10. 
Tauhid Nubuwwah (Kenabian) dan Sam'iyyat (Qur'an dan Hadits). ${ }^{38}$ Sedangkan Hasan al-Banna membagi rungan lingk up pendidikan tauhid menjadi empat bagian, yaitu:

1) Ilahiyat

Ilahiyat yaitu pembahasan tauhid mengenai segala sesuatu yang berhubungan dengan Allah SWT, seperti wujud Allah, nama-nama Allah dan dan sifat-sifat-Nya serta perbuatan Allah SWT. Menurut Ziyadi, penanaman nilai ilahiyat secara mendasar yaitu iman, Islam, ihsan dan taqwa. ${ }^{39}$

2) Nubuwat

Nubuwat yaitu membahas tentang segala sesuatu yang berhubungan dengan Nabi dan Rasul Allah, termasuk membahas tentang Kitab-kitab Allah dan hal-hal yang berkaitan dengan tugas Nabi.

3) Ruhaniyat

Ruhaniyat yaitu segala sesuatu yang membahas tentang alam metafisik atau alam ghaib, misalnya, malaikat, alam jin, iblis, roh dan sebagainya.

4) Sam'iyat

Sam'iyat yaitu segala sesuatu yang dapat diketahui lewat sam'i yaitu pemberitaan dari dalil naqli baik dari Al-Qur'an dan $\mathrm{Al}$-Hadits, misalnya tentang surga dan neraka, alam barzah, azab kubur, alam akhirat, tandatanda kiamat dan hal

\footnotetext{
${ }^{38}$ Abdul Jabbar Adlan, et.all., Teks Book, Dirosat Islamiyah, Pengantar Ilmu Tauhid dan Pemikiran Islam, (Surabaya: Aneka Bahagia, 1995), hlm. 37.

${ }^{39}$ Abdul Majid dan Dian Andayani, Pendidikan Karakter Perspektif Islam, (Bandung: Rosda, 2013), hlm. 93.
} 
lain yang sifatnya hanya pengabaran yaitu dari wahyu dengan melalui kitab suci Allah.

\section{Imam Ahmad bin Hambal}

Imam ahmad bin Hanbal lahir di Baghdad, kota Maru/Mery pada Rabiulawal $146 \mathrm{H}$ bertepatan dengan November $780 \mathrm{M}$. Nama lengkapnya adalah Abu Abdillah ahmad ibn Muhammad ibn Hanbal ibn Hilal ibn Asad ibn Idris ibn Abdllah ibn Hayyan ibn Abdillah ibn Anas ibn Awf ibn Qasit ibn Mazin ibn Syaiban ibn Zulal ibn Ismail ibn Ibrahim. $^{40}$ Orang-orang lebih mengenalnya sebagai ibn Hambal diambilkan dari nama kakeknya, hal ini disebabkan karena kakaeknya lebih terkenal dibandngkan ayahnya. Ibn Hanbal merupakan Gubernur di Sarakhs, Khurasan pada masa Daulah Umayyah. Ayahnya meninggal pada saat ia masih kecil, selanjutnya ia diasuh ibunya yaitu Syatiyah binti Maimunah binti Abdul Malik Asy-Syaibani dari Bani Amir. Pada saat berziarah ke Basrah, ia menyempatkan untuk shalat di Masjid Mazinbani Syaiban dan ia berkata "sesungguyhnya masjid ini adalah masjid nenek moyangku. ${ }^{41}$

Ahmad ibn Handal dibesarkan di Baghdad hingga usia 19 tahun. Pada usia relative muda ia sudah menghafalkan al Qur'an, pada 16 tahun ia juga telah belajar hadits dan ia selalu pergi pagi-pagi dan pergi kemasjid-masjid hingga ibunya merindukannnya. Pada $183 \mathrm{H}$ ia pergi ke Kuffah, 186 ke Bashrah, 187 ke Makkah dilanjutkan ke Madinah, 197 ke Yaman, Siria, Mesopotamia. Ahmad bin Hanbal mempelajari hadis dari Abu Yusuf Ya'qub bin Ibrahim al-Qodhi seorang ahl al ra'yi pengikut Abu Haifah dan juga belajar kepada Hasyim bin Basyirbin hlm. 25 .

${ }^{40}$ Al-Fatih Suryadilaga (ed), Studi Kitab-kitab Hadits, (Yogyakarta: Teras, Cet.1, 2003),

${ }^{41}$ Ahmad Asy-Syurbasy, al-Aimmah al-Arba'ah, Terj., Futuhul Arifin, 4 Mutiara Zaman Biografi Empat Imam Mazhab, (Jakarta: Pustaka Qalani, Cet. 1, 2003), hlm. 168. 
Abu Hazim al-Wasithy selama 4 tahun dan mengambil hadits dan menulisnya sebanyak 3000 hadits. ${ }^{42}$

Selanjutnya Ahmad bin Hanbal berguru kepada Imam Syafi'i pada musim haji di masjidil Haram, selanjutnya di Baghdad. Ia belajar tentang pemahaman istinbath (pengambilan hokum) atau penyimpulan sebuah hukum. Ini yang kemudian menjadikan Muhammad bin Ishak bin Khuzimah berkata: "ahmad ibn Hanbal adalah murid Imam Syafi'i". 43

Ahmad bin Hanbal yang lahir pada 164 bertepatan dengan masa kekhalifahan Musa al Mahdi (169-170) dari Abasiyah. Ahmad bin Hanbal wafat di Baghdad pada $241 \mathrm{H}$ pada masa kekuasaan alMutawakkil (228 - 242 H), saat itu dinasti Bani Abbas sedang menuju kehancurannya. ${ }^{44}$ Penguasa di Bgahdad baik dari Bani Abbas ataupun dari Bani Umayyah, mereka tidak menerima kritik dan oposisi. Ahmad bin Hanbal tidak pernah memfatwakan seorang khalifah dari golongan tertentu. Ia berpendapat jika; "mendengarkan dan taat pada pemimpin adalah wajib, baik ia baik ataupun fajir". Ia berpendapat bahwasannya mentaati khalifah yang durhaka lebih baik daripada kaum muslim menghadapi bencana yang tidak hanya menimpa orang-orang dzalim saja, namun juga akan menimpa orang-orang yang tidak bersalah juga. Pemberontakan akan mendatangkan kedzaliman lebih besar, pemberontakan mengaandung bencana atau malapetaka bahkan pertumpahan darah orang tidak berdosa. ${ }^{45}$

\footnotetext{
${ }^{42}$ Ahmad Asy-Syurbasy, al-Aimmah al-Arba'ah, Terj., Futuhul Arifin, 4 Mutiara Zaman Biografi Empat Imam Mazhab, (Jakarta: Pustaka Qalani, Cet. 1, 2003), hlm. 172.

${ }^{43}$ Imam Munawwir, Mengenal Pribadi 30 Pendekar dan Pemikir Islam dari Masa ke Masa, (Surabaya: Bina Ilmu, Cet. 1, 1985), hlm. 296.

${ }^{44}$ Jaih Mubarok, Sejarah dan Perkembangan Hukum Islam, (Bandung: Remaja Rosdakarya, Cet. 2, 2000), hlm. 196.

${ }^{45}$ Abdurrahman Asy-Syarqowi, A'immah al-Fiqh al-Tis'ah, Terj. M. Hamid al-Husaini, Riwayat Sembilan Imam Fiqih, (Bandung: Pustaka Hidayah, Cet. 1, 2000), hlm. 466.
} 
Meski awalnya Ahmad bin Hanbal berpendapat demikian, namun kemudian ia kemudian memiliki pendapat jika taat kepada khalifah yang dzalim merupakan salah satu bentuk kemunafikan yang harus dijauhi oleh orang beriman. Pendapat ini setelah ia melihat kesengsaraan serta penderitaan rakyat akibat pemimpin yang zalim dan durhaka. Sikap dan sifat Ahmad bin Hanbal merupakan refleksi dekadensi sosial dan kehancuran moral pada masa itu, kesemrawutan politik dan ekonomi, perpecahan teologis filosofis dan tekanan yang dihadapi rakyat semakin memperlebar jarak antara penguasa dan rakyat dan semakin meningkatnya ancaman terhadap masyarakat muslim. $^{46}$

Kaum mu'tazilah merupakan penasehat resmi otokrasi Abasiyyah, doktrin penciptaan al Qur'an secara politis digunakan untuk menekan tikoh masyarakat, buruh dan budak. Masyarakat dicekam rasa katakutan menghadapi ujian yang bisa mengantarkan mereka menghadapi mihnah. Mihnah adalah pengadilan atau penganiayaan yang diinkuisisi Mu'tazilah pada 218 -234 sebagai dogma resminya adalah al Qur'an mahluk bukan penciptaan. Di depan khalifah Abasiyyah al Mu'tazim Ahmad bin Hanbal dicambuk dan dipenjarakan karena tidak mengakui bahwa al Qur'an adalah mahluk. Ahmad mempertahankan pendiriannya bahwa al-Qur'an bukan makhluk sehingga pada tahun $220 \mathrm{H}$ dia dihukum, dipukul dan didera.b Pada masa pemerintahan al-Wasiq Ahmad dibuang dari Baghdad, ketika al-Mutawakil menjadi khalifah pada tahun $232 \mathrm{H} / 846 \mathrm{M}$, ia

${ }^{46}$ Abdurrahman Asy-Syarqowi, A'immah al-Fiqhal-Tis'ah, Terj. M. Hamid al-Husaini, Riwayat Sembilan Imam Fiqih, (Bandung: Pustaka Hidayah, Cet. 1, 2000), hlm. 37. 
menarik dekrit resmi mengenai khalqal-Quran dan Ahmad ibn Hanbal pun dibebaskandari penjara. ${ }^{47}$

Cara berijtihadnya Imam Ahmad bin Hambal tidak jaub berbeda dengan cara-cara berijtihadnya Imam Syafdi'i, ini dilatarbelakangi adanya hubungan guru dan murid. Adapun cara yang digunakan oleh Imam Ahmad bin Hambal dalam berijthad dibangun atas 5 dasar yaitu: Al-Nushus yaitu al-Quran dan hadits, Fatwa sahabat, Pendapat sahabat yang dekat dengan al-Qur'an dan Sunnah, Hadits mursal dan hadits dhaif dan Qiyas.

a. Al-Nushus yaitu al-Quran dan hadits

Al-Quran yaitu perkataan Allah SWT yang diturunkan oleh ruhulamin ke dalam hati Rasulullah dengan lafadz bahasa Arab, agar supaya menjadi hujjah bagi Rasulullah bahwa dia adalah utusan Allah SWT. ${ }^{48}$ Sedangkan al-Hadits yaitu segala ucapan, segala perbuatan, dan segala keadaan atau perilaku Nabi SAW. ${ }^{49}$

Menurut Imam Ahmad ibn Hanbal al-Qur'an adalah sumber pertama dalam menggali sumber hukum fiqh dia. Sedangkan sunnah sendiri adalah penjelas al-Quran dan tafsir hukumhukumnya. Maka tidak aneh apabila ia menjadikan al-Qur'an dan sunnah sebagai perintis sumber-sumber bagi pendapat fiqh dia. Oleh karena itu ia menolak terhadap orang-orang yang mengambil teks-teks al-Qur'an dan meninggalkan sunnah. Dalam pendahuluan bantahannya ia berkata: "Sesungguhnya Allah SWT telah mengutus Muhammad dan menurunkan kitab-Nya dengan

${ }^{47}$ Abdurrahman Asy-Syarqowi, A 'immah al-Fiqh al-Tis'ah. . . ., hlm. 37.

${ }^{48}$ Abdul Wahab Khallaf, Ilmu Usul Fiqh, Terj. Hallmudin, (Jakarta: Rineka Cipta, Cet. 5, 2005), hlm. 17.

${ }^{49}$ Mohmmad Ahmad dan Mudzakir, Ulumul Hadits, (Bandung: Pustaka Setia, Cet. 2, 2000), 12. 
membawa petunjuk bagi yang mengikutinya."Rasulullah adalah penjelas dari kitab Allah SWT danpemberi petunjuk terhadap makna-makna al-Qur'an. ${ }^{50}$ Bila jawaban atas persoalan hukum sudah didapat dalam nash-nash al-Qur'an dan hadits, ia tidak beranjak ke sumber lain, tidak pula menggunakan metode ijtihad.

b. Fatwa sahabat

Setelah Nabi Muhammad SAW wafat, sahabat sebagai generasi Islam pertama meneruskan ajaran dan misi kerasulan. Sahabat melakukan penelaahan terhadap al-Quran dan sunnah dalam menyelesaikan suatu kasus. Apabila tidak didapatkan dalam al-Quran dan sunnah, mereka melakukan ijthad dalam menyelesaikan kasus disebut fatwa, yaitu suatu pendapat yang muncul karena adanya peristiwa yang terjadi. Jadi fatwa sahabat merupakan ijtihad parasahabat dalam menyelesaikan suatu kasus.

Sahabat-sahabat yang terkenal sebagai mufti atau mujtahid adalah:

1) Zaid ibn Tsabit (nama lengkapnya Zaid ibn Tsabit ibn Dhalak al-Anshari).

2) Abdullah ibn Abbas (nama lengkapnya Abdullah ibn Abbad Abdul Mutholib).

3) Abdullah ibn Mas'ud (nama lengkapnya Abdullah ibn Mas'ud ibn Ghafal).

Apabila Imam Ahmad mendapat fatwa dari seorang sahabat dan ia tidak mendapatkan bantahan dari sahabat yang lain maka iamenjadikan pendapat tersebut sebagai hujjah.

c. Pendapat sahabat yang dekat dengan al-Qur'an dan sunnah.

${ }^{50}$ Ahmad Asy-Syurbasy, al-Aimmah al-Arba'ah . . , hlm. 176. 
Apabila Imam Ahmad ibn Hanbal mendapatkan fatwa dari beberapa sahabat maka ia mengambil pendapat yang menurutnya lebih dekat dengan al-Qur'an dan sunnah. Ia tidak pernah meninggalkan pendapat-pendapat sahabat untuk membuat ijtihad sendiri. Jika dia tidak yakin pendapat mana yang lebih dekat dengan al-Qur'an dan as- Sunah maka dia menerangkan seluruh perbedaan pendapat tersebut tanpa menegaskan pendapat mana yang harus diambil. ${ }^{51}$

d. Hadits mursal dan dhaif.

Hadits ini dipakai apabila tidak ada keterangan atau pendapat yang menolaknya. Pengertian mengenai hadits dhaif pada masa dahulu tidak sama dengan pengertiannya di zaman sekarang. Pada masa Imam Ahmad ibn Hanbal hanya ada dua macam hadits: hadits shahih dan hadis dhaif. Dimaksud dhaif disini bukan dhaif yang batil dan yang mungkar, tetapi merupakan hadits yang tidak berisnad kuat yang tergolong sahih atau hasan. Menurut Ahmad hadits tidak terbagi atas sahih, hasan dan dhaif tetapi sahih dan dhaif. Pembagian hadits atas sahih, hasan, dan dhaif dipopulerkan oleh al-Turmudzi. ${ }^{52}$ Hadits-hadits dhaif ada bertingkat-tingkat, yang dimaksud dhaif disini adalah pada tingkat yang paling atas. Menggunakan hadits semacam ini lebih utama dari pada menggunakan qiyas.

e. Qiyas

Apabila hadits mursal dan hadits dhaif sebagaimana disyaratkan di atas tidak didapatkan, Imam Ahmad ibn Hanbal hlm. 30 .

${ }^{51}$ Al-Fatih Suryadilaga (ed), Studi Kitab-kitab Hadits, (Yogyakarta: Teras, Cet.1, 2003),

${ }^{52}$ Muhammad Zuhri, Hukum Islam dalam Lintasan Sejarah, (Jakarta: Raja Grafindo Persada, Cet. 2, 1997), hlm. 124. 
menganalogikan (menggunakan qiyas) dalam pandangannya, qiyas adalah dalil yang dipakai dalam keadaan terpaksa. ${ }^{53}$

\section{Nilai-Nilai Pendidikan Tauhid Imam Ahmad bin Hambal}

Ajaran tauhid merupakan prinsip dasar dari semua ajaran agama, para Nabi dan Rasul untuk mengesakan Allah dan meninggalkan segala penyembahan kepada selain Allah. Nabi dan Rasul membawa ajaran tauhid, tetapi ada perbedaan di dalam pemaparan mengenai prinsip-prinsip tauhid. Perbedaan mengenai prinsip-prinsip tauhid tersebut di karenakan tingkat kedewasaan berfikir masing-masing manusia berbeda-beda, sehingga Allah SWT menyesuaikan tuntutan yang di anugerahkan kepada para Nabi-Nya sesuai dengan tingkat kedewasaan berfikir umat tersebut. ${ }^{54}$

Nabi Muhammad SAW diutus oleh Allah SWT untuk melanjutkan perjuangan Nabi sebelumnya dalam pemaparan tauhid, pada masa itu, pengenalan mengenai Allah dimulai dari perbuatan dan sifat Allah yang dapat dilihat dari wahyu pertama turun yaitu diawali dengan kata iqra" yang artinya bacalah.

Nilai atau value dalam bahasa Latin valere dan dalam bahasa perancis kuno disebut valoir, ${ }^{55}$ dapat dimaksani sebagai harga. Nilai adalah kualitas sesuatu yang menjadikannya disukai, dihargai, dïnginkan, berguna, bermanfaat dan membuat setiap orang yang memghayatinya menjadi bermartabat. Nilai bersifat abstrak, harganya mensifati dan disifatkan pada suatu hal dan ciri-cirinya yang dapat

${ }^{53}$ Jaih Mubarok, Sejarah dan Perkembangan Hukum Islam, (Bandung: Remaja Rosdakarya, Cet. 2, 2000), hlm. 120.

${ }^{54}$ M. Quraish Shihab, Wawasan Al-Qur'an, (Bandung: Mizan, 2015), hlm. 19. hlm. 7.

${ }^{55}$ Rohmat Mulyana, Mengartikulasikan Pendidikan Nilai, (Bandung: Alfabeta, 2011), 
dilihat dari tingkah laku, norma, moral dan juga keyakinan. ${ }^{56}$ Muhmidayeli berpendapat, nilai adalah suatu gambaran yang indah, mempesona, menakjubkan, membuat bahagia, senang dan menjadikan seseorang atau sekelompok orang ingin memilikinya (Muhmideyali, 2013: 101).

Nilai pendidikan merupakan suatu bimbingan atau pengajaran kepada peserta didik untuk menyadari nilai kebaikan, keindahan, dan kebenaran dengan melalui proses pertimbangan nilai yang tepat dan pembiasaan bertindak yang konsisten. ${ }^{57}$

Nilai pendidikan harus dipahami dan dihayati oleh manusia karena mengarah kepada sesuatu yang baik maupun yang buruk dan berguna bagi kehidupan manusia yang diperoleh dengan melalui proses pengubahan perilaku dalam upaya mendewasakan diri dengan proses pengembangan intelektual secara berkesinambungan.

Nilai-nilai pendidikan tauhid merupakan suatu hal yang utama dan merupakan masalah pertama yang dikedepankan, karena semua proses dalam pendidikan akan berakhir atau bermuara pada keesaan Allah dan pengakuan akan kebesaran Allah SWT.

Nilai pendidikan tauhid sangat penting bagi keberlangsungannya hidup umat manusia, jika seseorang menolak tauhid maka hidupnya akan sengsara dunia dan akhirat, sehingga setiap manusia memiliki fitrah sejak lahir ke dunia, maka kita perlu menjaga fitrah tersebut agar menjadi manusia yang benar-benar bertauhid kepada Allah SWT.

${ }^{56}$ Ade Imelda Frimayanti, Implementasi Pendidikan Nilai dalam Pendidikan Agama Islam, al Tadzkiyah jurnal Pendidikan Islam, Vol 6, November 2015, hlm. 201.

${ }^{57}$ Rohmat Mulyana, Mengartikulasikan Pendidikan Nilai ..., hlm. 11. 
Menurut Majid, bahwa pendidikan tauhid adalah seluruh kegiatan umat manusia dalam bidang pendidikan yang menempatkan Allah SWT sebagai sumbernya, sehingga pendidikan keimanan merupakan salah satu ruang lingkup dan tujuan utama dalam pendidikan Islam, untuk membawa individu dalam merealisasikan taqwa dalam diri seseorang. ${ }^{58}$

Imam ahmad bin Hanbal beserta ulama fiqih lainnya yaitu Imam Abu Hanifah, Imam Malik, Imam Asy-Syafi'i adalah ulama fiqih yang paling masyhur. Hal ini terbukti dari ilmunya, baik masalah fiqih, aqidah, dan juga karyanya. Mereka adalah orang yang layak dijadikan panutan bagi umat Islam dalam masalah agama. Nilai-nilai pendidikan tauhid Imam Hamad bin Hambal dapat dilihat dari hubungannnya kepada Allah SWT, diri sendiri dan kepada sesama manusia.

Imam Ahmad bin Hanbal memiliki kekuatan hafalan dan analisisnya, hal ini merupakan sifat umum para ahli hadits dan pemimpin secara khusus, sifat ini juga dimilki oleh Imam Malik dan Imam Asy-Syafici dari kalangan fuqaha yang mewariskan kekayaan fiqih, pemikiran, dan istinbath. ${ }^{59}$

Beliau ahli dalam bidang fiqih, hadits, dan dalam bidang tauhid, beliau memiliki kedudukan yang istimewa di bidang tersebut, beliau mencurahkan seluruh kemampuannya untuk menekuni bidangnya.

Tauhid menurut Imam Ahmad yaitu bersaksi bahwa tiada ilah yang berhak diibadahi kecuali Allah, tiada sekutu bagi-Nya, dan Muhammad adalah hamba dan utusan-Nya, serta mengakui semua

\footnotetext{
${ }^{58}$ Abd. Majid, Pendidikan Berbasis Ketuhanan Membangun Manusia Berkarakter, (Bogor: Ghalia Indonesia, 2014), hlm. 4.

${ }^{59}$ Abdul Aziz Asy-Syinawi, Biografi Empat Imam Mazhab, (Jakarta: Ummul Qura, Cet. 1, 2017), hlm. 679.
} 
yang disampaikan para Nabi dan Rasul, menyamakan dengan sifatsifat yang dipakai oleh mensifati diri-Nya sendiri dan tinggalkanlah hal-hal yang ditinggalkan oleh Allah SWT.

Nilai pendidikan tauhid menurut Imam Ahmad bin Hanbal yaitu perkataan dan perbuatan, bisa bertambah dan berkurang, bertambah jika berbuat kebaikan dan berkurang jika melakukan keburukan. Seseorang bisa keluar dari iman menuju Islam, kemudian jika ia bertobat, ia kembali lagi pada iman. ${ }^{60}$

Pokok-pokok sunnah Imam Ahmad bin Hanbal yaitu berpegang teguh kepada Al-Qurean dan As-Sunnah dan berpegang teguh kepada apa yang para sahabat Rasulullah SAW berada di atasnya dan meneladani mereka.

Dari penjelasan di atas, dapat diketahui bahwa tauhid adalah perkataan dan perbuatan, bersaksi bahwa tiada ilah yang berhak diibadahi kecuali Allah, tiada sekutu bagi-Nya, dan Muhammad adalah hamba dan utusan-Nya, serta mengakui semua yang disampaikan para Nabi dan Rasul.

Menurut Imam Al-Ghazali dalam kitab Ihya Ulumuddin, bahwa tauhid adalah dasar pokok yang termasuk di dalam ilmu mukasyafah, ilmu tersebut berhubungan dengan amal perbuatan dengan perantara hal-hal mengenai keadaan. Ilmu mamalat tidak akan sempurna tanpa amal-amal perbuatan yang menjadi buah dari hal keadaan, dan hal tersebut dapat membuahkan amal perbuatan. ${ }^{61}$

Menurut pendapat Imam Al-Ghazali di atas, bahwa tauhid memiliki hubungan erat dengan ilmu dan keadaan. Ilmu yang

${ }^{60}$ Abdul Aziz Asy-Syinawi, Biografi Empat Imam Mazhab . . , hlm. 748.

${ }^{61}$ Imam Al Ghazali , Ringkasan Ihya'Ulumuddin, (Jakarta: Pustaka Amani, 2009), hlm. 327. 
diamalkan dan bersifat meragukan akan membuahkan hasil dan ilmu tentang tauhid yaitu ilmu yang melingkup semua hal di atas, hal ini di karenakan Allah SWT melingkupi segala sesuatu.

Pemahaman mengenai tauhid akan menghasilkan suatu ilmu yaitu tauhid dan ilmu tersebut yang akan di amalkan. Seorang muslim yang telah berhasil dalam pemahaman tauhid yang sesungguhnya, akan mengetahui bahwa tauhid itu penting dan harus disampaikan kepada siapa saja dengan cara yang benar.

Nilai pendidikan tauhid merupakan suatu proses pendidikan yang berorientasi pada tauhid. Dilihat dari segi etimologi, tauhid yaitu mengesakan Allah. Mentauhidkan yaitu meyakini keesaan Allah baik dalam hal rububiyyah, uluhiyah dan asma wa' sifat Allah SWT.

Pendidikan tauhid merupakan sisitem penanaman nilai-nilai tauhid kepada umat manusia agar dapat memperkuat kataatan dan keimanan kepada Allah SWT, sehingga pendidikan dan nilai-nilai tauhid tidak dapat dipisahkan, karena pada hakikatnya sumber ilmu itu dari Allah SWT.

Kedudukan tauhid dalam Islam sangat fundamental, sehingga keimanan seorang muslim mulai tumbuh dilihat dari pemahamannya terhadap tauhid, karena tauhid adalah salah satu pokok ajaran yang sangat berpengaruh terhadap keislaman seorang muslim, jika pemahamannya terhadap tauhid tidak kuat, maka akan goyah pula keislamannya secara menyeluruh.

Kalimat tauhid "La Ilaha Illallah" yang artinya tidak ada Tuhan selain Allah, kalimat ini adalah bentuk dari persaksian seorang muslim. Kalimat yang sederhana tetapi maknanya yang menjadikan seseorang diakui sebagai seorang muslim dan menghantarkannya 
kepada Allah dalam keadaan tunduk dan patuh kepada-Nya. Sebagaimana firman Allah SWT, Artinya :

"Dan Kami tidak mengutus seorang Rasulpun sebelum kamu melainkan Kami wahyukan kepadanya: "Bahwasanya tidak ada Tuhan (yang hak) melainkan Aku, Maka sembahlah olehmu sekalian akan aku". Q.S. Al-Anbiyaa' $: 25 .{ }^{62}$

Ayat di atas menjelaskan bahwa Allah SWT telah mengutus seorang Nabi untuk mengembalikan manusia yang melakukan kesyirikan kepada selain Allah agar kembali kepada tauhid dan beriman hanya kepada

Allah SWT serta mengikuti ajaran agama yang telah dibawa oleh utusan Allah.

Melihat dari pengertian La Ilaha Illallah dapat di pahami bahwa manusia tidak ada tempat bersandar, berharap dan berlindung kecuali Allah SWT. Tetapi, persaksian yang benar tidak hanya pada ucapan lisan dan pembenaran hati, melainkan harus di sertai dengan amalan yang sesuai dengan ketentuannya, baik secara lahiriyah maupun bathiniyah.

Dengan kalimat La Ilaha Illallah seorang muslim telah memutlakkan Allah sebagai pencipta dan tidak ada selain-Nya. Dengan dasar kalimat tauhid ini, maka pendidikan tauhid menjadi suatu yang vital dalam kehidupan karena dengan di bekali dasar tauhid seorang muslim akan ingat kepada Allah.

Pemahaman terhadap tauhid dapat menghantarkan kita agar lebih memahami konsep tauhid rububiyyah, uluhiyyah dan asmae wa sifat Allah. Tauhid uluhiyyah sering disebut dengan tauhid ibadah

${ }^{62}$ Departemen Agama RI, Mushaf AL-Qur'an Terjemah ..., hlm. 324. 
karena tauhid ini semua bentuk ibadah dan lainnya harus dikerjakan hanya kepada Allah dan tidak boleh kepada selain Allah.

Percaya kepada tauhid rububiyyah Allah, maka harus disertai dengan percaya kepada uluhiyah dan asmae wa sifat Allah, karena ketiga tauhid ini tidak dapat di pisahkan dan saling berkaitan satu sama lain, tauhid uluhiyah tergantung dengan adanya tauhid rububiyyah, dan di dukung oleh tauhid asma' wa sifat.

Islam mengajarkan kepada umat muslim bahwa Allah menjadi inti dari pengalaman dan Allah adalah tujuan akhir, yakni semua tujuan tertuju dan berakhir. Inti sari dari agama Islam adalah tauhid yakni sebuah pengakuan kepada Allah SWT sebagai Tuhan Yang Maha Esa.

Berdasarkan penjelasan di atas, nilai-nilai pendidikan tauhid perspektif Imam Ahmad bin Hanbal dapat dikelommpokkan menjadi tiga nilai utama yaitu: nilai-nilai perilaku seorang muslim dalam hubungannnya kepada Allah SWT, diri sendiri dan kepada sesama manusia.

a. Nilai Pendidikan Tauhid Dalam Hubungannya Kepada Allah SWT

1) Tauhid Rububiyyah

Tauhid rububiyyah mempunyai pengertian bahwa beriman hanya kepada Allah SWT, Allah adalah satu-satunya Rabb yang memiliki, menciptakan, mengatur, merencanakan, memberikan manfaat, menolak madharat, menghidupkan dan mematikan serta menjaga seluruh alam semesta. Sebagaimana firman Allah SWT, artinya:

"Allah menciptakan segala sesuatu dan Dia memelihara segala sesuatu”. Q.S. Az-Zumar : $62 .{ }^{63}$

${ }^{63}$ Departemen Agama RI, Mushaf AL-Qur'an Terjemah ... hlm. 465. 
Ayat di atas menjelaskan bahwa setiap umat muslim wajib memiliki tauhid rububiyyah, karena ini adalah syarat keabsahan dari tauhid uluhiyah untuk sebagai syarat diterimanya suatu amal ibadah. Inti dari nilai tauhid rububiyyah yaitu :

a) Tauhid rububiyyah adalah mengesakan Allah dalam segala perbuatanNya dan meyakini bahwa Allah adalah yang menciptakan seluruh makhluk yang ada di alam semesta ini.

b) Meniadakan sekutu bagi Allah SWT dalam kekuasaanNya.

Implikasi nilai tauhid rububiyyah dalam kehidupan seharihari yaitu menjadikan manusia untuk dapat konsisten dalam hal mengakui keesaan Allah SWT sebagai pencipta, dan mengingatkan manusia untuk selalu bersyukur atas nikmat yang diberikan Allah kepada makhluk-Nya.

Nilai pendidikan tauhid yang terdapat dalam tauhid rububiyyah adalah manusia meyakini bahwa Allah SWT yang memiliki, menciptakan serta memelihara segala sesuatu yang ada di alam semesta ini.

2) Tauhid Uluhiyah

Tauhid uluhiyah diartikan beriman bahwa Allah yang berhak di sembah dan tidak ada sekutu bagi-Nya. Tauhid uluhiyah yaitu percaya sepenuhnya bahwa Allah yang berhak menerima semua peribadatan makhluk, manusia beribadah, bersujud, tempat bergantung dan memohon pertolongan hanya kepada Allah SWT. Sebagaimana firman Allah SWT, artinya: 
"Allah menyatakan bahwasanya tidak ada Tuhan melainkan Dia (yang berhak disembah), yang menegakkan keadilan. Para Malaikat dan orang-orang yang berilmu (juga menyatakan yang demikian itu). tak ada Tuhan melainkan Dia (yang berhak disembah), yang Maha Perkasa lagi Maha Bijaksana”. Q.S. AliImran : $18 .{ }^{64}$

Berdasarkan ayat di atas bahwa Allah SWT mengajarkan kepada umat muslim untuk menyembah dan berdoa hanya kepada Allah bukan kepada selainnya, berdasarkan niat taqarrub yang di syariatkan oleh Allah.

Sehingga tercabutlah segala bentuk kesyirikan yang ada di bumi ini. Inti dari ajaran nilai tauhid uluhiyah adalah :

a) Tauhid uluhiyah adalah mengesakan Allah dengan perbuatan para hamba-Nya berdasarkan niat taqarub seperti, berdoa, tawakal, pengharapan.

b) Tauhid uluhiyah adalah inti dari dakwah para Rasul.

Implikasi nilai tauhid uluhiyah dalam kehidupan seharihari yaitu mampu melaksanakan ibadah mahdhah hanya kepada Allah SWT dan melaksanakannya sesuai dengan tata cara yang telah di contohkan oleh Rasulullah SAW, serta mampu menerapkan ibadah, ammah yaitu sosial dengan bijak dan adil.

Nilai pendidikan tauhid uluhiyah yaitu setelah umat muslim meyakini atas keesaan Allah sebagai pencipta, pengatur, pemelihara, maka bentuk pengabdian kepada Allah dapat diwujudkan dengan cara peribadatan yang sesuai dengan syariat Islam.

${ }^{64}$ Departemen Agama RI, Mushaf AL-Qur'an Terjemah ... hlm. 52. 
3) Tauhid Asma' Wa Sifat

Tauhid asma' wa sifat adalah menetapkan nama-nama dan sifat-sifat yang sudah ditetapkan Allah sesuai dengan apa yang telah disifati untuk diri-Nya dan menafikan atau menolak sifat yang dinafikan Allah terhadap diri-Nya, baik dari kitab suci AlQur"an maupun As-Sunnah. Inti nilai tauhid Asmae Wa Sifat yaitu :

a) Allah meniadakan sesuatu yang menyerupai-Nya dan Allah yang menetapkan bahwa Dia Yang Maha Mendengar dan Yang Maha Melihat.

b) Mengimani nama-nama dan sifat-sifat Allah.

Implikasi nilai tauhid asma' wa sifat dalam kehidupan sehari-hari yaitu selalu konsisten dalam mengakui keesaan Allah SWT yang memiliki nama-nama dan sifat-sifat yang baik, dan mengajarkan umat muslim untuk mengenal nama-nama dan sifat-sifat Allah serta memperbanyak dzikir setiap waktu.

Nilai pendidikan tauhid asma, wa sifat adalah dengan menetapkan nama-nama dan sifat-sifat Allah yang telah disifati oleh Allah untuk diri-Nya yang ada di dalam Al-Qur"an, dan yang telah di tetapkan oleh Rasulullah SAW dalam As-Sunnah yang shahih tanpa taewil, tafwidh, tamsil, dan ta"thil.

Imam ahmad bin hanbal beserta imam fiqih lainnya menegaskan hubungannya kepada Allah yaitu mereka beriman hanya kepada Allah SWT, yakin atas keesaan Allah bahwa Allah pencipta alam semesta, serta percaya akan nama-nama dan sifat-sifat Allah SWT yang ada di dalam Al-Qur'an.

b. Nilai Pendidikan Tauhid dalam Hubungannya Kepada Diri Sendiri 


\section{1) Aqidah}

Manusia diciptakan oleh Allah di atas aqidah yang satu, yaitu tauhid. Seorang muslim wajib memiliki aqidah yang benar dan bersih agar terhindar dari penyimpanganpenyimpangan aqidah. Aqidah merupakan jalan yang baik dalam menyatukan kaum muslimin untuk memperbaiki urusan dunia dan akhirat.

2) Ibadah

Ibadah yaitu merendahkan diri kepada Allah SWT yaitu dengan tingkatan tunduk dan disertai dengan rasa kecintaan kepada Allah, dalam melaksanakan ibadah harus merujuk kepada sunnah Rassulullah yang berarti tidak boleh ada unsur penambahan dan pengurangan.

Amalan suatu ibadah dapat diterima, ditolak, bahkan dapat menjadi perbuatan dosa, karena amal tersebut adalah maksiat, dan bukan ketaatan. Pelaksanaan ibadah yang benar atau disyariatkan yaitu sikap pertengahan, yaitu antara meremehkan dan malas dengan sikap ekstrim serta melampaui batas.

Hubungan empat ulama mazhab fiqih kepada diri sendiri yaitu dengan aqidah dan ibadah, mereka memiliki aqidah yang satu yaitu mengikuti Al-Qur'an dan Hadits serta mengikuti perkataan-perkataan para sahabat dan ibadah mereka dilakukan dengan rasa kecintaan kepada Allah SWT.

c. Nilai Pendidikan Tauhid dalam Hubungannya Kepada Sesama Manusia

1) Dakwah Tauhid

Nabi dan Rasul selalu memulai dakwahnya dengan mengajak umatnya kepada tauhid, karena tauhid merupakan 
dakwah yang paling utama dan mulia. Menyeru kepada tauhid merupakan hal yang pertama kali disampaikan, dan tidak boleh mengedepankan suatu kewajiban apapun daripada tauhid.

Tauhid adalah tujuan Allah mengutus Nabi dan Rasul, perilaku manusia dalam mendakwahkan manusia kepada jalan tauhid diwujudkan dengan cara mengajak keluarga dan masyarakat untuk menjadi meraih predikat yang mulia sebagai kekasih Allah.

2) Ihsan Kepada Manusia

Ihsan kepada manusia yaitu berbuat baik kepada orang lain dengan niat yang tulus dan penuh kasih sayang, Allah SWT menyukai orang yang bersikap ihsan kepada sesama manusia, lebih-lebih sikap tersebut dilakukan terhadap orang tua.

Perilaku manusia dalam ihsan kepada manusia dapat diwujudkan dengan mengajak keluarga dan masyarakat dalam berkompetensi dalam hal kebaikan dan senantiasa saling tolong menolong dalam keadaan apapun.

Hubungan empat ulama mazhab fiqih dengan sesama manusia yaitu dengan berdakwah tauhid serta ihsan kepada sesama manusia, karena dakwah tauhid adalah suatu hal yang utama dan mulia dan berbuat berbuat baik kepada sesama manusia dilakukan dengan niat yang tulus.

\section{Kesimpulan}

Berdasar pada uraian pembahasan di atas, dapat disimpulkan bahwasannya pendidikan tauhid merupakan proses penanaman ketauhidan atas keesaan Allah SWT. Ini penting untuk ditanamkan kepada manusia khususnya umat muslim dari sejak dini sekalipun. Imam Ahmad bin Hanbal sebagai salah satu ulama fiqh memiliki pendapat 
Jurnal Pendidikan Agama Islam Universitas Wahid Hasyim Semarang

yang tidak jauh berbeda dengan ulama fiqih lainnya tentang tauhid dan nilai-nilai pendidikan tauhid. Hal ini dipertegas dalam peryataannya yaitu beriman hanya kepada Allah SWT, yakin atas keesaan Allah dan Allah pencipta alam semesta, serta percaya akan nama-nama dan sifatsifat Allah SWT yang ada di dalam Al-Qur'an. Nilai-nilai pendidikan tauhid Imam Ahmad bin Hanbal dapat dikelommpokkan menjadi tiga nilai utama yaitu: nilai-nilai perilaku seorang muslim dalam hubungannnya kepada Allah SWT, diri sendiri dan kepada sesama manusia. 
Jurnal Pendidikan Agama Islam Universitas Wahid Hasyim Semarang

\section{DAFTAR PUSTAKA}

Adlan, Abdul Jabbar et.all. 1995. Teks Book, Dirosat Islamiyah, Pengantar Ilmu Tauhid dan Pemikiran Islam. Surabaya: Aneka Bahagia.

Afandi, Syahrizal. 2019. Kajian Hadits Jibril dalam Persepektif Pendidikan (Kajian Materi Pembelajaran dan Metode Pembelajaran), Jurnal Penelitian KeIslaman, Vol. 15, No. 1. https://journal.uinmataram.ac.id/index.php/ipk/article/view/525

Ahmad, Mohmmad dan Mudzakir. 2000. Ulumul Hadits. Bandung: Pustaka Setia.

Ahmadi, Abu dan Nur Uhbiyati. 2013. Ilmu Pendidikan Islam. Jakarta: Rineka Cipta.

Ahmadi, Abu Nur Uhbiyati. 2015. Ilmu Pendidikan. Jakarta: Rineka Cipta.

Al Ghazali, Imam. 2009. Ringkasan Ihya' Ulumuddin. Jakarta: Pustaka Amani.

Al Maududi, Abu A'la. 1975. Prinsip-prinsip Islam. Terj, Abdullah Suhaili, Bandung: al Ma'arif.

Al-Faruqi, Ismail Raji. 1988. Tauhid, Terj. Rahmani Astuti, Bandung: Pustaka.

Al-Qaradhawi, Yusuf. 2006. Akidah Salaf dan Kholaf. Jakarta: Pustaka al Kausar.

Anwar, Choirul. 2014. Hakikat Manusia dalam Pendidikan Sebuah Tinjuan Filosofis, Yogyakarta: Pustaka Setia.

Asy-Syarqowi, Abdurrahman. 2000. A'immah al-Fiqh al-Tis'ah. Terj. M. Hamid al-Husaini, Riwayat Sembilan Imam Fiqih. Bandung: Pustaka Hidayah.

Asy-Syinawi, Abdul Aziz. 2017. Biografi Empat Imam Mazhab. Jakarta: Ummul Qura.

Asy-Syurbasy, Ahmad. 2003. al-Aimmah al-Arba'ah, Terj., Futuhul Arifin, 4 Mutiara Zaman Biografi Empat Imam Mazhab. Jakarta: Pustaka Qalani.

At-Tamimi, Abdurrahman. 1991. Al-Mathlub al-Hamid fi Bayani Maqasid atTauhid, Yogyakarta: Darul Hidayah.

Departemen Agama RI. 2014. Mushaf AL-Qur'an Terjemah, Banadung: Diponegoro.

Fauzan, Asy Syaikh. 2006. al-Qoulul Mufid Penjelasan tentang Tauhid. Bandung: Darul Ilmi.

Frimayanti, Ade Imelda. Implementasi Pendidikan Nilai dalam Pendidikan Agama Islam. al Tadzkiyah jurnal Pendidikan Islam. Vol 6. November 2015.

Gunawan, Heri. 2014. Penddikan Islam: Kajian Teoritis dan Pemikiran Islam, Bandung: Remaja Rosdakarya. 
Jurnal Pendidikan Agama Islam Universitas Wahid Hasyim Semarang

Hamdani, M. 2013. Pendidikan Ketuhanan dalam Islam. Surakarta: UMS Press.

Karim, Abdul. 2013. Manhaj Imam Ahmad ibn Hanbal dalam Kitab Musnad. RIWAYAH. Vol. 1, No.2, September 2015. https//journal.iainkudus.ac.id/index.php/riwayah/issue/view/170.

Karsadi. 2011. Pendidikan Kewarganegaraan di Perguruan Tinggi Membangun Karakter Bangsa, Kendari, Unhalupress.

Khaldun, Ibnu. 1986. Muqoddimah, Terj. Ahmadie Thoha, Jakarta: t.p.

Khallaf, Abdul Wahab. 2005. Ilmu Usul Fiqh. Terj. Hallmudin. Jakarta: Rineka Cipta.

Latif, Abdul Aziz bin Muhammad Alu Abdul. 2008. Pelajaran Tauhid untuk Pemula. Jakarta: Darul Haq.

M Yusran Asmuni dari Tim Penyusun Kamus. 1993. Kamus Besar Bahasa Indonesia, Jakarta: Departemen P\&K 1989, dalam Ilmu Tauhid, Jakarta: Raja Grafindo Persada.

Mahbudi, M. 2012. Pendidikan Karakter: Implementasi Aswaja sebagai Nilai Pendidikan Karakter. Yogyakarta: Pustaka Ilmu.

Majid, Abd. 2014. Pendidikan Berbasis Ketuhanan Membangun Manusia Berkarakter. Bogor: Ghalia Indonesia.

Majid, Abdul dan Dian Andayani. 2013. Pendidikan Karakter Perspektif Islam. Bandung: Rosda.

Marzuki. 2005. Ahmad bin Hanbal (Pemikiran Fikih dan Ushul Fikihnya), Jurnal Hunafa, Vol. 2, No. Agustus. 107-118. https $/ /$ www.jurnalhunafa.org/index.php/hunafa

Mubarok, Jaih. 2000. Sejarah dan Perkembangan Hukum Islam. Bandung: Remaja Rosdakarya.

Muhmideyali. 2013. Filsafat Pendidikan. Bandung: Refika Aditama.

Mulyana, Rohmat. 2011. Mengartikulasikan Pendidikan Nilai. Bandung: Alfabeta

Mulyono dan bashori. 2010. Studi Ilmu Tauhid / Kalam. Malang: UIN Maliki Press.

Munawwir, Imam. 1985. Mengenal Pribadi 30 Pendekar dan Pemikir Islam dari Masa ke Masa. Surabaya: PT. Bina Ilmu.

Nasir, Sahilun. 2010. Pemikiran Kalam, Teologi Islam: Sejarah, Ajaran dan Perkembangannya. Jakarta: Rajawali.

Nasution, Harun. 1996. Islam Rasional: Gagasan dan Pemikiran. Jakarta: Mizan.

Nasution, Harun. 2011. Akal dan Wahyu dalam Islam. Jakarta UI Press.

Noer, Hery. 2015. Ilmu Pendidikan Islam, Jakarta: Bumi Aksara.

Razin, Abu dan Nur Fajri Ramadhan. 2016. Pokok AkidahAhlussunah - Imam Ahmad bin Hanbal (dengan Pendekatan Nahwu dan Sharaf). Depok: BISA. 
Jurnal Pendidikan Agama Islam Universitas Wahid Hasyim Semarang

Rozak, Abdul dan Rosihan Anwar. 2012. Ilmu Kalam. Bandung: Pustaka Setia.

Sanusi, Achmad. 2017. Sistem Nilai Alternatif Wajah-wajah Pendidikan. Bandung: Nuansa Cendikia.

Shalih bin Fauzan. 2009. Kitab Tauhid Juz I. Jakarta: Darul Haq.

Shalih. 2001. Kitab tauhid I. Yogyakarta: Universitas Islam Indonesia.

Shihab, M. Quraish. 2015. Wawasan Al-Qur'an. Bandung: Mizan.

Suryadilaga, Al-Fatih (ed). 2003. Studi Kitab-kitab Hadits. Yogyakarta: Teras.

Syafe'i, Imam. 2017. Pondok Pesantren: Lembaga Pendidikan Pembentukan Karakter. Tadzkiyyah Jurnal Pendidikan Islam, Volume 8 No 1, November.

Tafsir, Ahmad. 2010. Filsafat Pendidikan Islam: Integrasi jasmani, Rohani dan Kalbu. Bandung: Remaja Rosdakarya.

Yazid, Muhammad Taqi Misbah. 2003. Filsafat Tauhid, Terj., M. Ha bin Wicaksana, Bandung: Mizan.

Zainuddin. 2015. Ilmu tauhid Lengkap. Jakarta: Rineka Cipta.

Zakiyah, Qiqi Yuliati dan A Rusdina. 2014. Pendidikan Nilai Kajian Teori dan Praktik di Sekolah, Bandung: Pustaka Setia.

Zuhairini. 2012. Filsafat Pendidikan Islam. Jakarta: Bumi Aksara.

Zuhri, Muhammad. 1997. Hukum Islam dalam Lintasan Sejarah, Jakarta: Raja Grafindo Persada. 